\title{
Benzodiazepine use and associated factors in elderly in the city of Dourados, MS, Brazil
}

\author{
Uso de benzodiazepínicos e fatores associados em \\ idosos na cidade de Dourados, MS, Brasil
}

Christiane Dias dos Anjos Cunha', Maria Cristina Corrêa de Souza', Graziella Almeida Andrade Cattanio', Stephanie Ramirez lahnn', Rosangela da Costa Lima²

\section{ABSTRACT}

Objective: The use of benzodiazepines (BZD) and associated factors in the elderly of Dourados, MS, Brazil was investigated. Methods: This is a cross-sectional population-based study using a multistage sampling design. Participants were 1,022 individuals aged $\geq 60$ years. Measurements: socioeconomic status, schooling, demographic aspects, marital status, physical activity, hospitalizations, self-rated health, use of alcohol beverages and smoking were assessed by standard questionnaire. The drugs used were obtained by checking the prescription or package and classified according to the Anatomical Therapeutic Chemical Index. Chi-square test, Chi-square for linear tendency, Fisher's exact test and Poisson regression were used to assess association between variables. Results: The prevalence of use of BZD was 6.5\% (C195\%: 5.1-8.2\%). The oldest group (PR: 1.60 for $70-79$ years and PR:

\section{Keywords}

Elderly, aging;

benzodiazepines, cross-sectional studies, anxiolytics. 1.79 for $\geq 80$ years), non-use of alcohol (PR: 4.14) and use of antidepressants (PR: 8.73) were the statistically associated characteristics. Conclusions: The prevalence of use of BZD in the study population was low, similar to findings of more recent Brazilian studies and lower than those obtained in international studies. The prevalence of use of BZD increased with aging and use of antidepressants.

\section{RESUMO}

Objetivo: Foi investigado o uso de benzodiazepínicos (BZD) e fatores associados em idosos no município de Dourados, MS. Métodos: Delineamento transversal, de base populacional com amostra de conglomerados estratificada e em múltiplos estágios. Os participantes totalizaram 1.022 indivíduos com idade $\geq 60$ anos. Foi utilizado questionário padronizado com as variáveis nível econômico, escolaridade, demográficas, situação conjugal, exercícios físicos, internações hospitalares, autopercepção de saúde, uso de bebida alcoólica e fumo. Os medicamentos utilizados foram obtidos por meio da verificação da receita médica ou embalagem e classificados segundo o Anatomical Therapeutic Chemical Index. Para avaliar a associação entre as variáveis foram utilizados os testes do qui-quadrado, de tendência linear, exato de Fisher e regressão de Poisson. Resultados: A prevalência do uso de BZD foi de 6,5\% (IC95\%: 5,1-8,2\%). A maior idade (RP: 1,60 para 70-79 anos e RP: 1,79 para $\geq 80$

1 Federal University of Grande Dourados (UFGD), College of Health Sciences, Pos-Graduate Program in Health Sciences. 2 National Council for Scientific and Technological Development (CNPq)-Brazil; UFGD, College of Health Sciences, Post-Graduate Program in Health Sciences. 


\section{Palavras-chave}

Idoso, envelhecimento, receptores

benzodiazepínicos, estudos transversais, ansiolíticos. anos), o não uso de bebidas alcoólicas (RP: 4,14) e o uso de antidepressivos (RP: 8,73) foram as características estatisticamente associadas. Conclusões: A prevalência do uso de BZD na população estudada foi baixa, semelhante à de outros estudos brasileiros recentes e menor do que as obtidas em estudos internacionais. A prevalência do uso de BZD aumentou com a idade e o uso de antidepressivos.

\section{INTRODUCTION}

In the nineteenth century, decline in fertility levels and growth of older population were observed, being related to increased quality of life, decline in mortality, urbanization, nutritional improvement, growing vaccination coverage, sanitation and water supply, scientific and technology advances and higher educational level ${ }^{1,2}$.

According to the United Nations, the world elderly population will increase by $11.0 \%$ between 2000 and $2050^{3}$. The projection of the Brazilian Institute of Geography and Statistics (IBGE), in Brazil, includes an increase in the number of older people greater than 15.0\% between 2010 and $2015^{4}$.

This growth in the older population associated with noncommunicable chronic diseases that affect this age group results in greater need for health care services, and, consequently, in governmental investments in public health ${ }^{5}$. This fact has directly influenced the general use of drugs including benzodiazepines (BZD) by older people ${ }^{6}$. The use of these substances has been associated, in the elderly, to increased number of falls ${ }^{7-9}$, decreased cognitive functioning ${ }^{10}$, dementia ${ }^{11}$ pneumonia' ${ }^{12}$, weight gain and adverse effects on glycidic and lipid metabolisms ${ }^{13}$. Despite the risks inherent to using these substances, they bring important benefits for the elderly including: reduced anxiety, decreased fear, greater social participation, sleep induction and maintenance, muscle relaxing effects and treatment and prevention of epileptic seizures ${ }^{14}$.

Few studies have assessed the prevalence of benzodiazepines use in elderly. In Brazil, the prevalence rates range from 6.1 to $21.7 \%$ and up to $32 \%$ in international studies ${ }^{7,15-23}$. In this context, the aim of this study was to investigate whether the prevalence of use of BZD in the Midwestern region differs from other regions. Furthermore, the socioeconomic profile, demographic aspects, health habits and characteristics of elderly people who live in the city of Dourados, MS, Brazil, were evaluated.

\section{METHODS}

A cross-sectional study was conducted, and the sample was composed of individuals of both genders, aged 60 years and above, living in the urban area of the city of Dourados, Mato do Grosso do Sul, Brazil. Institutionalized people (nursing homes, hospitals, prisons) and indigenous people were excluded from the sample.
Sample size was calculated using the EPI-INFO 3.5.2 software (Center for Diseases Control and Prevention, Atlanta, USA). The parameters used were the estimated prevalence of BZD use of $21.7 \%{ }^{15}$, with confidence interval of $95 \%$, sampling error of three percentage points, design effect of 1.8 and an estimate of 17.805 individuals aged 60 years or above, living in the urban zone of the City of Dourados ${ }^{4}$. With an additional $10 \%$ to compensate for losses and refuses, the sample totaled 790 people. However, since this research integrates the study titled "A saúde dos idosos em Dourados, MS" (The health of elderly people in Dourados, MS) which assessed several aspects related to the health of older people, the sample was larger.

The study incorporated a multistage stratified systematic sampling scheme. For the definition of the number of households to be visited, the study sample was divided by the number of people per household (3.2), multiplied by the percentage of elderly in the population (0.09), according to data from IBGE4.

The number of households to be visited was estimated to be 3.507 , which was divided by 30 households per sector, giving 120 census tracts, to which four additional sectors were added.

The 295 urban census tracts of Dourados were listed, arranged into ascending order by factor analysis of variables, literacy rate, waste collection, sewage treatment and piped water - variables used as a proxy of the socioeconomic status - and systematically selected.

A pilot study was conducted in a census tract of the target-population with 50 elderly people, which was not included in the study, to assess the adequacy of the questionnaire for the study objectives.

The sectors selected were covered from the threshold defined by IBGE. The number of households recorded by the 2010 Demographic Census in the sector was divided by 30 households to be visited by sector in order to obtain the jump number. The following households were systematically determined by the addition of the jump number.

The interviews were preceded by a visit where the objectives of the study were explained, and in the case of agreement, the age of all household members was asked. In households with elderly individuals, the residents were informed that the interviewers would return to collect data.

Data were collected using standardized questionnaire applied by trained interviewers. When respondents were not able to take part in the survey (1.7\%), a close relative or 
caregiver was asked to answer the questionnaire, except for self-rated health.

The dependent variable was use of BZD, including its related drugs. Participants were asked about the use of any medication in the last 15 days. Drug names were confirmed by direct inspection of the prescription or medication bottles. Drugs were classified according to therapeutic category using the Anatomical Therapeutical Chemical Classification System (ATC) by a pharmacist.

The independent variables included information on socioeconomic status (classified as A/B, C and D/E according to the Brazilian Association of Research Companies - ABEP); schooling $(0 ; 1-3 ; 4-11 ; \geq 12)$; age (years); gender (male; female); selfreferred skin color or race (white/yellow; black/brown); marital status (married/living with a partner; single/widowed/separated/divorced); practice of physical exercises (yes; no); use of alcohol in the last 30 days (yes; no); smoking (yes; no); number of hospitalization in the last 12 months $(0 ; 1 ; \geq 2)$; use of antidepressants in the last 15 days (yes; no) and self-rated health status (excellent/very good; good; poor/very poor).

The questionnaires were revised, coded and double-entered using Epidata software, version 3.1 (The Epidata Association, Odense, Denmark). The final database was converted to STATA 13.0 statistical package (Stata Corp., College Station, Texas, USA). Descriptive statistics was used to characterize BZD users and included Chi-square, Chi-square for linear tendency or Fisher's exact test. The association magnitude was assessed by calculating prevalence ratios with their respective confidence intervals (95\%) by Poisson regression. In multivariable analysis, all variables were included and removed in decreasing order of $p$-value, and only variables with $p<0.05$ remained at the end of analyses. Data analysis considered the design effect (STATA's svy command).

The proposal was approved by the Ethics Research Committee of Federal University of Grande Dourados (Protocol No. 001/2011). Written informed consent was obtained from all participants.

\section{RESULTS}

Among selected households, 1,121 people were eligible for the study. Of these, 48 refused to participate $(4.3 \%)$ and 51 were not available after three visits (4.5\%), totaling 1,022 individuals interviewed from June to September, 2012.

The use of BZD in the last 15 days was reported by $6.5 \%$ of elderly people (C195\%: 5.1\%-8.2\%). The average number of BZD used per individual was $1.15( \pm 0.4) ; 86.4 \%$ used only one type of BZD, $12.1 \%$ used two and $1.5 \%$ used three. The most frequently used BZD were clonazepam (28.8\%), diazepam (18.2\%), alprazolam (12.1\%) and bromazepam (10.6\%).

Half of participants (50.4\%) were classified according to $\mathrm{ABEP}$ as being in socioeconomic level $\mathrm{C}$ and regarding school- ing, $40.4 \%$ of respondents studied from 4 to 11 years. The average age of participants was $70.78( \pm 8.2)$ and the predominant age range was $60-69$ years (55.9\%), $57.7 \%$ were female, $55.3 \%$ declared themselves white/yellow and $56.1 \%$ lived with a partner. The use of BZD increased with aging $(p<0.001)$, among females $(p<0.001)$ and those living without a partner $(p=$ 0.029). Regarding behavioral and health characteristics, $64.8 \%$ reported not practicing physical activity, approximately $70.0 \%$ did not drink alcohol in the last 30 days, $87.2 \%$ of participants did not smoke or were ex-smokers, $17.1 \%$ were hospitalized in the last 12 months and $11.0 \%$ reported the use of antidepressants. Approximately one-fifth of respondents described their health as poor/very poor. Not drinking alcohol beverages ( $p$ $<0.001)$, reporting hospitalizations in the last year $(p=0.002)$, use of antidepressants $(p<0.001)$ and self-rated health status as poor or very poor ( $p=0.035)$ showed significant statistical association with the use of BZD (data not shown).

Tables 1 and 2 present the multivariate analysis where crude and adjusted prevalence ratios were calculated. The use of BZD increased significantly with aging. Elderly aged

Table 1. Poisson regression analysis of benzodiazepine (BZD) use and socioeconomic and demographic characteristics in elderly in the city of Dourados, MS, Brazil, 2012 ( $n=1,022)$

\begin{tabular}{|c|c|c|c|}
\hline Characteristics & BZD use (\%) & Crude PRe $\left(C \mid 95 \%{ }^{f}\right)$ & Adjusted PRg (C195\% $\left.{ }^{f}\right)$ \\
\hline Socioeconomic (ABEP)a & $p=0.015^{b}$ & $p=0.060$ & \\
\hline$A / B$ & $9.2 \%$ & $2.36(1.23-4.56)$ & \\
\hline c & $6.4 \%$ & $1.64(0.84-3.22)$ & \\
\hline$D / E$ & $3.9 \%$ & 1.0 & \\
\hline Schooling (years) & $p=0.515^{b}$ & $p=0.160$ & \\
\hline 0 & $5.7 \%$ & 1.0 & \\
\hline $1-3$ & $7.7 \%$ & $1.36(0.73-2.51)$ & \\
\hline $4-11$ & $5.3 \%$ & $0.94(0.50-1.75)$ & \\
\hline$\geq 12$ & $11.9 \%$ & $2.10(1.00-4.45)$ & \\
\hline Age (years) & $\mathrm{p}<0.001^{\mathrm{b}}$ & $p=0.010$ & $p=0.049$ \\
\hline $60-69$ & $4.6 \%$ & 1.0 & 1.0 \\
\hline $70-79$ & $7.7 \%$ & $1.69(1.03-2.76)$ & $1.60(1.00-2.64)$ \\
\hline$\geq 80$ & $10.9 \%$ & $2.40(1.33-4.11)$ & $1.79(1.04-3.07)$ \\
\hline Gender & $\mathrm{p}<0.001^{\mathrm{c}}$ & $\mathrm{p}<0.001$ & \\
\hline Male & $3.5 \%$ & 1.0 & \\
\hline Female & $8.6 \%$ & $2.49(1.39-4.47)$ & \\
\hline Color or race referred & $p=0.306^{d}$ & $p=0.230$ & \\
\hline White/yellow & $7.3 \%$ & $1.33(0.84-2.10)$ & \\
\hline Black/brown & $5.5 \%$ & 1.0 & \\
\hline Marital status & $p=0.029^{d}$ & $p=0.030$ & \\
\hline $\begin{array}{l}\text { Married/living with a } \\
\text { partner }\end{array}$ & $4.9 \%$ & 1.0 & \\
\hline $\begin{array}{l}\text { Single/widowed/ } \\
\text { separated/divorced }\end{array}$ & $8.5 \%$ & $1.73(1.07-2.79)$ & \\
\hline
\end{tabular}

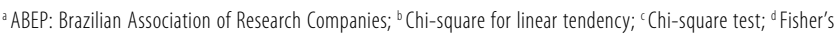

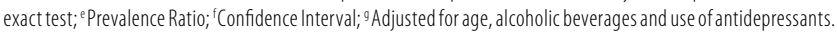


70-79 years used this medication 1.6 times more than individuals aged 60-69 years and elderly aged 80 years or older used it 1.8 times more than younger individuals. Respondents who did not report alcohol use in the past 30 days used BZD approximately four times more than those who reported drinking. Elderly people who reported the use of antidepressants in the past 15 days used approximately nine times more BZD. The other characteristics investigated here were not statistically associated with use of BZD.

Table 2. Poisson regression analysis of benzodiazepine (BZD) use and behavioral and health characteristics in elderly in the city of Dourados, MS, Brazil, 2012 ( $n=1,022$ )

\begin{tabular}{|c|c|c|c|}
\hline Characteristics & BZD use (\%) & Crude PR ${ }^{d}\left(C_{195 \%}{ }^{e}\right)$ & Adjusted PR (C195\% $\left.{ }^{\mathrm{e}}\right)$ \\
\hline Physical activity & $p=0.689^{a}$ & $p=0.590$ & \\
\hline Yes & $7.0 \%$ & $1.13(0.72-1.76)$ & \\
\hline No & $6.2 \%$ & 1.0 & \\
\hline Alcoholic beverages & $\mathrm{p}<0.001^{\mathrm{a}}$ & $p<0.001$ & $p=0.006$ \\
\hline Yes & $1.3 \%$ & 1.0 & 1.0 \\
\hline No & $8.6 \%$ & $6.56(2.38-18.08)$ & $4.14(1.51-11.36)$ \\
\hline Smoking & $p=1.000^{a}$ & $p=0.850$ & \\
\hline Yes & $6.1 \%$ & 1.0 & \\
\hline No/ex-smoker & $6.5 \%$ & $1.07(0.55-2.06)$ & \\
\hline $\begin{array}{l}\text { Hospitalizations (last } \\
12 \text { months) }\end{array}$ & $\mathrm{p}<0.001^{\mathrm{b}}$ & $p=0.002$ & \\
\hline 0 & $5.5 \%$ & 1.0 & \\
\hline 1 & $7.5 \%$ & $1.35(0.61-2.97)$ & \\
\hline$\geq 2$ & $16.4 \%$ & $2.96(1.58-5.53)$ & \\
\hline $\begin{array}{l}\text { Use of } \\
\text { antidepressants }\end{array}$ & $\mathrm{p}<0.001^{\mathrm{a}}$ & $\mathrm{p}<0.001$ & $\mathrm{p}<0.001$ \\
\hline Yes & $33.0 \%$ & $10.37(6.86-15.67)$ & $8.73(5.60-13.62)$ \\
\hline No & $3.2 \%$ & 1.0 & 1.0 \\
\hline Self-rated health & $p=0.011^{c}$ & $p=0.040$ & \\
\hline $\begin{array}{l}\text { Excelent/very } \\
\text { good }\end{array}$ & $3.3 \%$ & 1.0 & \\
\hline Good & $5.8 \%$ & $1.78(0.66-4.80)$ & \\
\hline Poor/very poor & $10.0 \%$ & $3.06(1.09-8.62)$ & \\
\hline
\end{tabular}

a Fisher's exact test; ${ }^{b}$ Chi-square test; ' Chi-square for linear tendency; ${ }^{\mathrm{P} R}$, Prevalence Ratio; ${ }^{\mathrm{e}} \mathrm{Cl}$, Confidence Interval; ${ }^{\dagger}$ Adjusted for age, alcoholic beverages and use of antidepressants.

\section{DISCUSSION}

The prevalence of BZD use in the 15 days prior to data collection was $6.5 \%$. This result was similar to findings obtained in Brazilian studies with similar recall periods in the city of São Paulo, SP $-6.1 \%^{17}$ and Campo Belo, MG - 9.3\% ${ }^{7}$, as well as in several regions of the United States of America (USA) - 9.9\% ${ }^{16}$.

Other locations showed higher prevalence rates. In Bambuí, MG, Brazil, the prevalence of use of BZD was $21.7 \%$ in the elderly, with a recall period of 90 days ${ }^{22}$. A study conducted in the Department of Gironde, France, obtained prevalence rate of $31.9 \%$ in the past two weeks ${ }^{18}$. In Quebec, Canada, prevalence rate of $32.0 \%{ }^{24}$ was obtained by means of personal interviews and confirmation of patient's records in the 12 months preceding the survey through the national health security number. These different results can be explained by the behavior of prescribers and some population characteristics evaluated such as the access to health services, epidemiology profile and social and cultural characteristics ${ }^{17}$. In addition, the different periods of drug use and the sample allocation can partly explain the quantitative differences in BZD use in these studies. Another aspect to be evaluated is the temporal question, that is, information collected before $2000^{7,15,16,18,21,25}$ appear to show higher prevalence of BZD use than more recent studies ${ }^{17,23}$, except for the study of Préville et al. than was collected in 2005-2006 and presented a prevalence of 32\% 24 .

The present investigation trained interviewers and assessed the use of drugs by checking the prescription or packaging of medications. This fact was also reported by some researchers, 15,16,18,23. However, other studies have confirmed the information on medications in electronic data records ${ }^{19,21,24}$. Regarding the recall period for the use of medications, respondents were asked about the use of the medications in the past 15 days. In other studies, the period included two previous weeks ${ }^{16,18}$, lately ${ }^{7}$, now $^{17,23}$, in the last 90 days $^{15}$ and in the 12 months prior to the survey ${ }^{24}$.

In the present study, predominant use of clonazepam (28.8\%), diazepam (18.2\%), alprazolam (12.1\%) and bromazepam (10.6\%) was observed. Clonazepam was also one of the most frequently medications used in some regions of Brazil and Canada: diazepam in Brazil and Sweden 7,15,17,26, alprazolam in the US $16,23,26$ and bromazepam in Brazil $7,15,17$. Other commonly used drugs were lorazepam in some regions of the United States and Canada16,18,21,23,24,26. As it can be seen, there are different medical prescriptions for elderly people, and in Brazil, the availability of clonazepam and diazepam through the Unified Health System (SUS) may contribute to the greater use of these drugs. There is concern with the regular use of diazepam and alprazolam, as well as with the association of two or three types of BZD by the elderly. Some studies have suggested that the use of various BZD by the elderly is associated to high risk of adverse effects, such as risk of fall and prolonged sedation. These facts result from pharmacodynamic and pharmacokinetic changes in the drugs, comorbidities and polypharmacy related to age, with smaller doses of BZD being recommended for this population ${ }^{27}$.

In the crude analysis of prevalence ratios (Tables 1 and 2), older elderly, women, living without a partner, no alcohol use, hospitalizations, use of antidepressants, and poor/very poor self-rated health status were associated to increased use of BZD. However, after controlling for confounding factors in multivariate analysis, only variables age, abstinence from alcohol and antidepressant use maintained a statistically significant association with use of BZD. The prevalence of use of BZD in the present study increased with aging PR: 1.60 
(C195\%: 1.00-2.64) and 1.79 (C195\%: 1.04-3.07), respectively of individuals aged $70-79$ and 80 years or above compared to younger individuals. A study conducted with the general population in a telephone interview in France found association between use of BZD and aging [35-44 years - OR: 3.1; (C195\%: 1.8-5.1); 45-59 years - OR: 6.1 (C195\%: 3.8-9.7) and 60 years or older - OR: 11.1 (CI95\%: 7.1-17.5) $]^{28}$, as in the present study. Analysis of the period of time of use of these medications showed that individuals aged over 75 years were more likely to use BZD for a long period ${ }^{24,29}$ and some authors claim that psychotropic drugs are the most suitable for this age group ${ }^{7,30}$. However, a population-based survey with elderly on BZD use did not detect age as a factor associated to the habit of using BZD ( $p>0.050)^{15,16,18}$. In the present study, most BZD users did not report drinking alcohol (PR: 4.1; C195\%: 1.5111.36). The same occurred with Gleason et al. ${ }^{16}$ who observed a higher average weekly alcohol consumption in individuals who did not use BZD - 2.7 more doses of alcohol than BZD users - 1.5 doses $\left(p<0.001\right.$ ). Nevertheless, Stowell et al. ${ }^{23}$ did not detect significant difference in alcohol use among BZD users or non-users. Not drinking alcohol beverages is possibly due to medical contraindications ${ }^{14,16}$. This recommendation is very important due to the risk of severe respiratory depression, a consequence of the depressant effect synergism, which may result in serious and fatal poisoning. This effect was observed in BZD and alcohol interaction in the first five doses of alcohol, equivalent to $1 \mathrm{~g} / \mathrm{kg}$ of ethanol ${ }^{31}$. Gleason et al. ${ }^{16}$ report that low alcohol consumption among BZD users can also be due to the fewer prescriptions of BZD among alcohol users.

Population-based survey with elderly aimed at investigating the use of psychotropic drugs found prevalence ratio of $2.45^{18}$, while in the present study, greater association was found (PR 8.73). This difference can be explained by the increased use of antidepressants worldwide ${ }^{32}$ and also to the prescriptive habits of Brazilian physicians. The concomitant use of antidepressant can be a consequence of depressive disorder, anxiety disorder or improper use of BZD 17,18,23,26, which could also be related to emotional or nervous disorder ${ }^{16}$, or depression can be associated to physical, mental and psychosocial problems ${ }^{30}$, making diagnosis difficult. Another study reported self-assessment of emotional or nervous disorder significantly associated to the use of BZD (OR: 6.66; C195\%: 5.09-8.71), but the consumption of antidepressants was not assessed $^{16}$, unlike the findings of Monongahela Valley, EUA, where depressive symptoms were not significantly associated to the use of BZD ${ }^{23}$. However, depressive symptoms not always characterize clinical depression, and it should be mentioned that users of antidepressants can be temporarily depressed ${ }^{18}$.

In the present study, socio-economic status showed no statistically significant difference in relation to the use of BZD, corroborating other studies ${ }^{15,16}$. Female gender was significantly associated with use of BZD only in the analysis of crude prevalence ratios, and was not maintained in the adjusted prevalence ratio. A previous study also found no association between female gender and greater use of BZD21. Self-reported skin color or race showed no statistically significant difference in relation to the use of BZD in this study. In some regions of the USA, white skin color was associated to 1.9 times higher use of BZD among elderly ${ }^{16}$. Living alone was only significant in the analysis of crude prevalence ratios. These results are similar to those obtained in previous studies, where being widower was only significant in univariate analysis ${ }^{15,18}$, or with non-significant results ${ }^{16}$. Behavioral variables such as practice of physical exercises and smoking showed no statistically significant differences in this survey, as in previous studies ${ }^{16,18}$. The number of hospitalizations in the past twelve months was associated with use of BZD only in the crude prevalence ratio analysis. Population-based surveys on the use of psychotropic drugs in elderly found hospitalization in the past year not significant ${ }^{17}$. However, few population-based studies on the use of BZD by elderly assessed this variable. Another factor associated only with crude prevalence ratio analysis was self-rated health status, in which elderly people who perceived their health as good used approximately twice as many BZD, and those with poor/very poor health used three times more BZD compared to those who perceived their health status as excellent/very good. Review articles mostly with cross-sectional studies have found that self-rated health status as poor would impact mental health and lead to the need of psychotropic drugs. However, the authors have suggested a longitudinal study to clarify this association ${ }^{33}$. It should be stressed that population aging results in specific demands and characteristics associated to the use of BZD that should be investigated.

One limitation of this study was the lack of information on the period of use of medications, which made further investigations difficult. Another limitation was the fact that BZD use consequences such as cognitive impairment, falls and pneumonia have not been studied. Moreover, the study design does not make it possible to establish temporal relationship between some variables.

\section{CONCLUSIONS}

It was concluded that the prevalence of use of BZD in the elderly in the past 15 days in the present study was low (6.5\%) compared to the prevalence rate observed in developed countries and similar to findings of more recent Brazilian studies. The prevalence of use of BZD increased with aging and use of antidepressants.

\section{INDIVIDUAL CONTRIBUTIONS}

Christiane D. A. Cunha - Study concept, data collection, preparation of manuscript. 
Maria C. C. Souza - Analysis and interpretation of data, preparation of manuscript.

Graziella A. A. Cattanio - Study concept, data collection, preparation of manuscript.

Stephanie R. Iahnn - Study concept, data collection, preparation of manuscript.

Rosangela C. Lima - Study concept, analysis and interpretation of data, preparation of manuscript. RCL was the coordinator of the study in all stages (design, methods, subject recruitment, data collections, analysis and preparation of paper), funded by National Research Council Brazil (CNPq Brazil).

\section{CONFLICTS OF INTEREST}

The authors (Christiane Dias dos Anjos Cunha, Maria Cristina Corrêa de Souza, Graziella Almeida Andrade Cattanio Stephanie Ramirez lahnn and Rosangela da Costa Lima) have no financial or any other kind of personal conflicts with this paper.

\section{ACKNOWLEDGMENTS}

The authors thank CNPq-Brazil for financing the project; CAPES, for granting the postgraduate scholarships; the interviewers and participants of the survey.

\section{REFERENCES}

1. Singh Z. Aging: the triumph of humanity-are we prepared to face the challenge?. Indian I Public Health. 2012;56(3):189-95.

2. World Health Organization (WHO). Definition of an older or elderly person. Available from: $<$ http://www.who.int/healthinfo/survey/ageingdefnolder/en/>. Accessed on: Apr 10, 2013.

3. United Nations. Department of Economic and Social Affairs: World population ageing 2009. Available from: <http://www.un.org/esa/population/publications/WPA2009/ WPA2009-report.pdf>. Accessed on: May 15, 2012.

4. Instituto Brasileiro de Geografia e Estatística (IBGE). Indicadores Sociodemográficos e de Saúde no Brasil, 2009. Available from: <http://www.ibge.gov.br/home/estatistica/populacao/indic_sociosaude/2009/indicsaude.pdf>. Accessed on: Feb 02, 2013.

5. Bloom DE, Canning D, Fink G. Implications of population ageing for economic growth. OXford Rev Econ Pol. 2010;26(4):583-612.

6. Haider SI, Johnell K, Thorslund M, Fastbom J. Trends in polypharmacy and potential drugdrug interactions across educational groups in elderly patients in Sweden for the period 1992 - 2002. Int J Clin Pharmacol Ther. 2007;45(12):643-53.

7. Chaimowicz F, Ferreira TJXM, Miguel DFA. Use of psychoactive drugs and related falls among older people living in a community in Brazil. Rev Saude Publica. 2000;34(6):631-5.

8. Coutinho ESF, Silva SD. Uso de medicamentos como fator de risco para fratura grave decorrente de queda em idosos. Cad Saude Publica. 2002;18(5):1359-66.

9. van Strien AM, Koek HL, van Marum RJ, Emmelot-Vonk MH. Psychotropic medications, including short acting benzodiazepines, strongly increase the frequency of falls in elderly. Maturitas. 2013;74(4):357-62.

10. Bierman EJ, Comijs HC, Gundy CM, Sonnenberg C, Jonker C, Beekman AT. The effect of chronic benzodiazepine use on cognitive functioning in older persons: good, bad or indifferent? Int J Geriatr Psychiatry. 2007;22(12):1194-200.

11. Gage SB, Bégaud B, Bazin F, Verdoux H, Dartigues JF, Pérès K, et al. Benzodiazepine use and risk of dementia: prospective population based study. BMJ. 2012;345:e6231.
12. Obiora E, Hubbard R, Sanders RD, Myles PR. The impact of benzodiazepines on occurrence of pneumonia and mortality from pneumonia: a nested case-control and survival analysis in a population-based cohort. Thorax. 2013;68:163-70.

13. Teixeira PJ, Rocha FL. Efeitos adversos metabólicos de antipsicóticos atípicos e estabilizadores de humor. Rev Psiquiatr Rio Gd Sul. 2006;28(2):186-96.

14. Baldwin DS, Aitchison K, Bateson A, Curran HV, Davies S, Leonard B, et al. Benzodiazepines: risks and benefits. A reconsideration. J Psychopharmacol. 2013;27(11):967-71.

15. Alvarenga JM, Loyola Filho Al, Firmo JO, Lima-Costa MF, Uchoa E. Prevalence and sociodemographic characteristics associated with benzodiazepines use among community dwelling older adults: the Bambuí Health and Aging Study (BHAS).Rev Bras Psiquiatr. 2008;30(1):7-11.

16. Gleason PP, Schulz R, Smith NL, Newsom JT, Kroboth PD, Kroboth FJ, et al. Correlates and prevalence of benzodiazepine use in community囚dwelling elderly. J Gen Intern Med. 1998;13(4):243-50.

17. NoiaAS, Secoli SR, Duarte YA0, Lebrão ML, Lieber NSR. Fatores associados ao uso de psicotrópicos por idosos residentes no Município de São Paulo. Rev Esc Enferm USP. 2012;46(Esp):38-43.

18. Fourrier A, Letenneur L, Dartigues JF, Moore N, Bégaud B. Benzodiazepine use in an elderly community-dwelling population. Characteristics of users and factors associated with subsequent use. Eur J Clin Pharmacol. 2001;57(5):419-25.

19. Gisev N, Hartikainen S, Chen TF, Korhonen M, Bell JS. Mortality associated with benzodiazepines and benzodiazepine-related drugs among community-dwelling older people in Finland: a population-based retrospective cohort study. Can J Psychiatry. 2011;56(6):377-81.

20. Winkelmayer WC, Mehta J, Wang PS. Benzodiazepine use and mortality of incident dialysis patients in the United States. Kidney Int. 2007;72(11):1388-93.

21. Tamblyn R, Abrahamowicz M, du Berger R, McLeod P, Bartlett G. A 5-year prospective assessment of the risk associated with individual benzodiazepines and doses in new elderly users. J Am Geriatr Soc. 2005;53(2):233-41.

22. Alvarenga JM, Loyola Filho Al, Firmo JOA, Lima-Costa MF, Uchoa E. A population based study on health conditions associated with the use of benzodiazepines among older adults (The Bambuí Health and Aging Study) Cad Saude Publica. 2009;25(3):605-12.

23. Stowell KR, Chang CC, Bilt J, Stoehr GP, Ganguli M. Sustained benzodiazepine use in a community sample of older adults. J Am Geriatr Soc. 2008;56(12):2285-91.

24. Préville M, BosséC, Vasiliadis HM, Voyer P, Laurier C, Correlates of potentially inappropriate prescriptions of benzodiazepines among older adults: results from the ESA study. Can J Aging. 2012;31(3):313-22.

25. Taipale HT, Bell JS, Gnjidic D, Sulkava R, Hartikainen S. Sedative load among communitydwelling people aged 75 years or older: association with balance and mobility. J Clin Psychopharmacol. 2012;32(2):218-24.

26. Martinsson G, Fagerberg I, Wiklund-Gustin L, Lindholm C. Specialist prescribing of psychotropic drugs to older persons in Sweden - a register-based study of 188024 older persons. BMC Psychiatry. 2012;12:197.

27. Mimica Matanović S, Vlahovic-Palcevski V. Potentially inappropriate medications in the elderly: a comprehensive protocol. Eur J Clin Pharmacol. 2012;68(8):1123-38.

28. Lagnaoui R, Depont F, Fourrier A, Abouelfath A, Bégaud B, Verdoux $H$, et al. Patterns and correlates of benzodiazepine use in the French general population. Eur J Clin Pharmacol. 2004;60(7):523-9.

29. Cunningham CM, Hanley GE, Morgan S. Patterns in the use of benzodiazepines in British Columbia: examining the impact of increasing research and guideline cautions against long-term use. Health Policy. 2010;97(2-3):122-9.

30. Blumstein T, Benyamini Y, Chetrit A, Mizrahi EH, Lerner-Geva L. Prevalence and correlates of psychotropic medication use among older adults in Israel: cross-sectional and longitudinal findings from two cohorts a decade apart. Aging Ment Health. 2012;16(5):636-47.

31. Aranko K, Seppälä T, Pellinen J, Mattila MJ. Interaction of diazepam or lorazepam with alcohol. Psychomotor effects and bioassayed serum levels after single and repeated doses. Eur J Clin Pharmacol. 1985;28(5):559-65.

32. Noordam R, Aarts N, Verhamme KM, Sturkenboom MC, Stricker BH, Visser LE. Prescription and indication trends of antidepressant drugs in the Netherlands between 1996 and 2012: a dynamic population-based study. Eur J Clin Pharmacol. 2015;71(3):369-75.

33. Noordam R, Aarts N, Verhamme KM, Sturkenboom MC, Stricker BH, Visser LE. Prescription and indication trends of antidepressant drugs in the Netherlands between 1996 and 2012: a dynamic population-based study. Eur J Clin Pharmacol. 2015;71(3):369-75. 